\title{
Appraisal on low cost and sustainable ECC using microfibers in hybridization at later age
}

\author{
Maninder Singh, Babita Saini* and H.D. Chalak \\ Department of Civil Engineering, National Institute of Technology, Kurukshetra, Haryana, India (136119) \\ Corresponding Author: bsaini6@nitkkr.ac.in \\ Submitted :04/03/2020 \\ Revised : :15/11/2020 \\ Accepted :24/11/2020
}

\begin{abstract}
The addition of supplementary cementitious materials and fiber plays an important role in the mechanical and durability performance of ECC matrix. In the present research work, the assessment of the performance of ECC matrix with the utilization of iron industry waste and microfibers has been done. Three types of microfibers, i.e., polyvinyl alcohol (PVA) fiber, polyester (PET) fiber, and microsteel (MSE) fiber, were used at various percentages in hybridization to prepare total seven mixes. First, PVA was switched by PET fiber at dosages 5\%, 10\%, 15\%, 20\%, and $25 \%$ and afterwards another $25 \%$ by MSE fiber. The performance of various matrix proportions was judged based on the flexural response, electrical resistivity, air permeability, and sorptivity characteristics to introduce sustainable and cost effective ECC matrix. Test results revealed that hybridization of fibers enhanced the flexural and durability performance of ECC and also produced a cost effective and sustainable ECC matrix.
\end{abstract}

Keywords: Polyester fiber; Sorptivity; Permeability; Slag; Micro pores; Resistivity.

\section{INTRODUCTION}

Cement based materials are most commonly used in the structural application fields. The cracks and penetration of detrimental liquids reduce the durability performance and service life of the concrete structures. Therefore, most of the cement-based structures damage and require repairing in continuity during service life. To enhance the mechanical and durability performance of structures, few decades ago high strength concrete (HSC) was introduced in construction industry, because, of its unique characteristics. The nature of HSC is considered as brittle which affects the other parameters i.e. ductility and crack width. From last three decades, lots of efforts have been made by researchers to overcome these drawbacks. In present time, the material used in structural applications must satisfy the condition of high strength, tiny cracks and ductility. Engineered cementitious composite (ECC) is the novel class of high-performance fiber reinforced cementitious material (HPFRCM), which can be used to overcome above mentioned requirements. The most superb characteristics of ECC is the high energy absorption capacity (equal to 30 $\left.\mathrm{KJ} / \mathrm{m}^{2}\right)$, high tensile strain capacity $(1 \%-8 \%)$ and controlled crack width $(<100 \mu \mathrm{m})$ (Singh et al., 2019 ${ }^{\mathrm{a}}$; Li et al., 1998 ; Singh et al., 2019 ; Li et al., 1998 ; Said et al., 2015; Sahmaran et al., 2009). Design of ECC rely on the theory of microcracks and fracture mechanics and it presents a strain hardening behavior with multiple tiny cracks (Sahmaran et al., 2009; Ranade et al., 2014; Li et al., 1994). Literature reported several types of ECC matrix such as sprayable (shotcrete ECC), lightweight, self-compacting and extruded (Li et al., 1998 ${ }^{\mathrm{a}}$; Shao et al., 1997; Kong et al., 2003; Kim et al., 2003). Despite the abovementioned characteristics of ECC, its use in structural applications is 
limited due to higher cost. The usage of higher amount of cement and polymeric fiber (polyethylene (PE) and polyvinyl alcohol (PVA) play the main role in increasing the cost of ECC. Most of the researchers used PVA and PE fibers to develop the ECC. The cost of PE fiber is 6 to 7 times the cost of PVA fiber. The nature of PVA fibers is hydrophilic which makes a strong chemical bond with cement matrix, resulting into fibers rupture than pullout (Redon et al., 2001 \& Pakravan et al., 2016). To decrease the bonding between matrix and fiber, oil treatment was applied on fiber surface, which increased the cost of fibers (Meng et al., 2017 \& Li et al., 2017).

Hybridization of fibers and inclusion of waste was mainly employed to decrease the cost of ECC and improve the fiber-matrix interaction. Numerous investigations reported that hybridization of low and high modulus fiber promote not only the unique characteristic; but, also reduced the cost of ECC. Low modulus fiber promotes the ductile nature and also contribute in high absorption capacity; whereas, high modulus fiber contribute in higher bridging strength and modulus of elasticity (Li et al., 2016). Combined use of PE and steel fiber in ECC revealed the better shear strength and deflection capacity and also enhanced the fiber bridging strength (Alrefaei et al., 2018). The use of steel and PVA fiber in hybridization revealed better energy absorption capacity, impact resistance and also enhanced the tensile strength and fiber bridging capability (Soe et al., 2013 ${ }^{\mathrm{a}}$ \& Soe et al., 2013 ${ }^{\mathrm{b}}$ ). Ali et al., 2017 reported that the combination of PVA and SMA (shape memory alloy) fiber enhanced the tensile capacity, flexural strength and changed the failure mode of conventional cement matrix from brittle to ductile. The hybrid usage of PP (Polypropylene) and PVA fiber enhanced the tensile strain capacity with decrease in the cost of ECC (Pakravan et al., 2016). Most of the research works conducted on hybridization, with steel and PVA fiber. The combined use of steel-PVA leads to decrease in superb characteristics of ECC (tensile strain capacity and deflection capacity) and beneficial for flexural strength, toughness, fiber bridging capability improvement (Li et al., 1996 \& Meng et al., 2018). However, previous studies reported that hybridization of fiber in ECC contribute in the enhancement of overall performance. Previous studies mainly focused on mechanical parameters and limited studies have been carried out on durability aspects of ECC matrix with the fiber combination. In past, lot of studies have been carried out on FRC (fiber reinforced concrete) with the use of various types of fibers such as steel, basalt, nylon, glass, textile, carbon, bagasse, PP, polyester (PET), PE, PVA etc., and the inclusion of these fibers in FRC enhanced the mechanical as well as durability performance of the matrix. The modulus of PET (polymeric) fibers is low and derived from virgin polyester. Utilization of PET fiber in cement-based products revealed better mechanical and durability performance than conventional concrete. Siddique et al., 2012 reported that the intrusion of PET fiber in HVFA (high volume fly ash concrete) concrete increased the abrasion resistance. The cost of PET fiber is very less as compared to PVA fiber. In present study mainly focus is on cost, sustainability and durability performance of ECC to promote its use in developing countries and hydraulic structures. PET fibers (polymeric nature) do not behave like hydrophobic or hydrophilic and distinctive features of PET make a very good bond between fiber and cement matrix (Rathod et al., 2010). Present research includes the hybrid proportion of PVA, PET, steel fiber and GGBFS (Ground granulated blast furnace slag) and performance of various mixes was evaluated based on flexural response, electrical resistivity, air permeability and sorptivity characteristics.

\section{CONSTITUENTS AND METHODS}

\section{Constituents Used}

Proper selection of constituents is the prime factor in design of ECC matrix. Ordinary Portland (43 grade) cement (OPC) confirming to IS 8112 (2013) and ASTM C150 was used. GGBFS waste as a cementitious material and microsilica sand (MSS) with 175 micron maximum size was used as a fine aggregate. The chemical composition of solid constituents is presented in Table 1 and Energy dispersive X-ray spectroscopy (EDS) images illustrated in Figure 1. Polyvinyl alcohol (PVA) fiber coated by $1.2 \%$ of engine oil, recron 3s polyester (PET) fiber and microsteel fiber (MSE) with brass coating were used as fibers reinforcement as shown in Figure 2. Typical properties of all the 
fibers used in this study are presented in Table 2. To achieve the proper flowability, master glenium SKY 8233 high performance plasticizer (SP) based on PCE (Polycarboxylic ether type) was used in all the ECC mixes.

Table 1. Chemical composition of solid constituents (EDS analysis).

\begin{tabular}{|c|c|c|c|}
\hline Chemical compounds (\%) & GGBFS & OPC & MSS \\
\hline $\mathrm{CaO}$ & 33.47 & 61.56 & ---- \\
\hline $\mathrm{SiO}_{2}$ & 41.39 & 21.92 & 99.99 \\
\hline $\mathrm{Al}_{2} \mathrm{O}_{3}$ & 18.61 & 7.18 & ---- \\
\hline $\mathrm{MgO}$ & 3.82 & 5.37 & ---- \\
\hline $\mathrm{Na}_{2} \mathrm{O}$ & 0.72 & 1.55 & ---- \\
\hline $\mathrm{K}_{2} \mathrm{O}$ & 0.81 & 1.15 & ---- \\
\hline $\mathrm{SO}_{3}$ & 1.18 & 1.27 & ----- \\
\hline
\end{tabular}

Table 2. Physical characteristics of fibers.

\begin{tabular}{|c|c|c|c|}
\hline Specifications & MSE & PET & PVA \\
\hline Diameter (mm) & 0.20 & $0.025-0.035$ & 0.04 \\
\hline Length (mm) & 13 & 12 & 12 \\
\hline Aspect ratio (L/D) & 65 & 400 & 300 \\
\hline Tensile strength (MPa) & 2000 & 480 & 1600 \\
\hline Elongation (\%) & --- & 30 & 42.8 \\
\hline Young's modulus (GPa) & --- & --- & 1.3 \\
\hline Density (g/cm $\left.{ }^{3}\right)$ & --- & 1.31 & Low \\
\hline Electrical conductivity & High & Low & \\
\hline
\end{tabular}

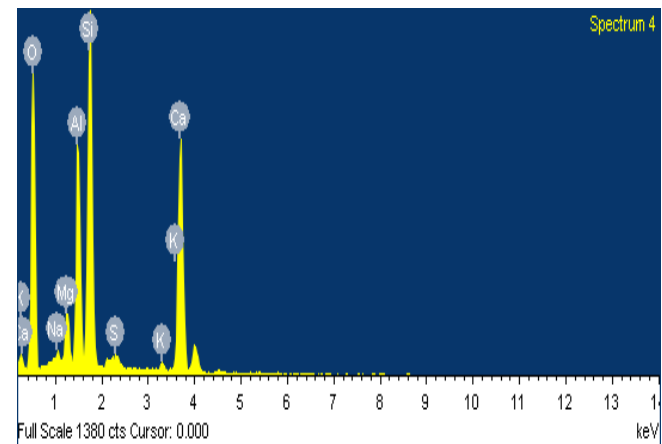

(a)

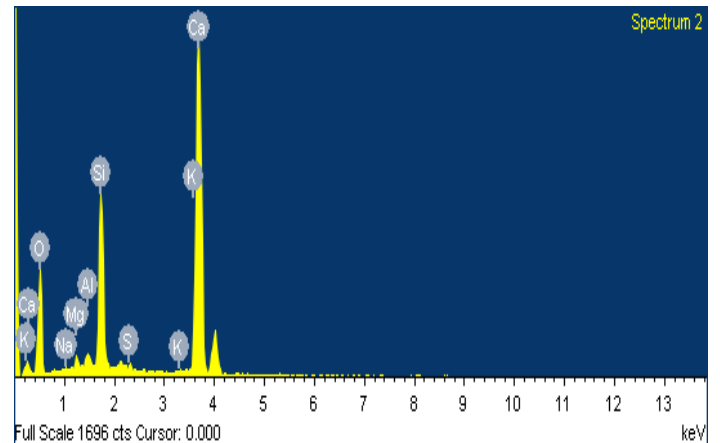

(b) 


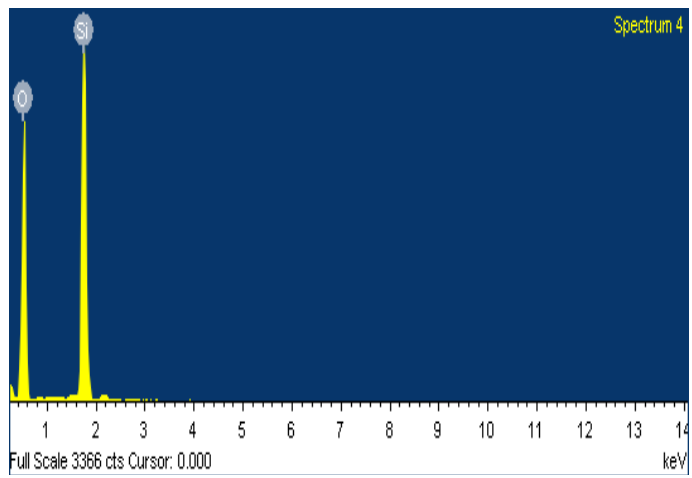

(c)

Figure 1. EDS of (a) GGBFS, (b) PC, and (c) MSS.

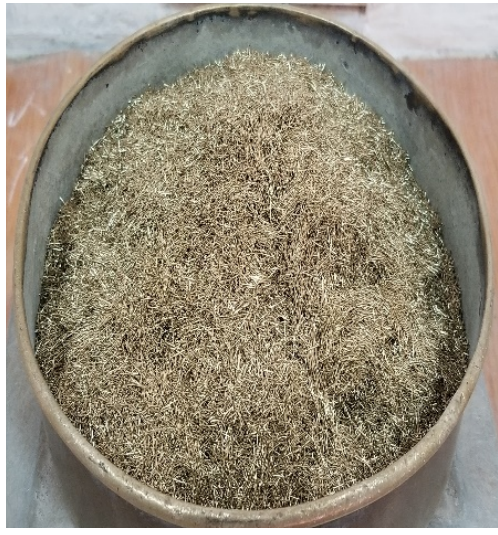

(a)

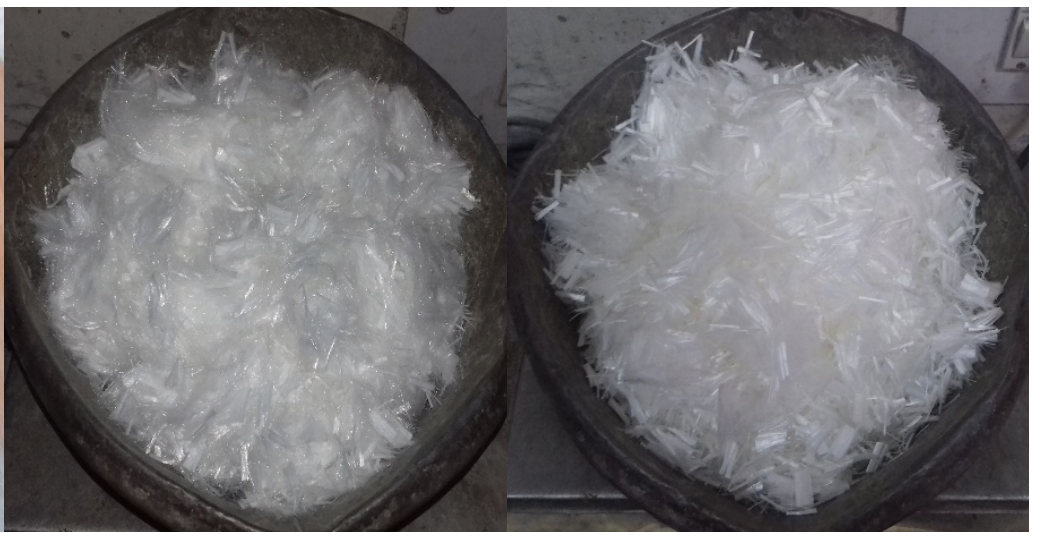

(b)

(c)

Figure 2. Pictorial view of fibers: (a) MSE, (b) PET, and (c) PVA.

\section{Matrix Proportions}

In present investigation proportions of matrix were divided into seven groups with the intrusion of PVA, PET and MSE fiber as listed in Table 3. The performance of ECC mixture was evaluated with the use of all three fibers in various combinations.

Table 3. Matrix proportions with hybridization of microfibers.

\begin{tabular}{|c|c|c|c|c|c|c|c|}
\hline \multirow{2}{*}{ Constituents } & \multicolumn{7}{|c|}{ Mix Designation } \\
\cline { 2 - 8 } & HS1 & HS2 & HS3 & HS4 & HS5 & HS6 & HS7 \\
\hline OPC & 1.0 & 1.0 & 1.0 & 1.0 & 1.0 & 1.0 & 1.0 \\
\hline GGBFS & 1.2 & 1.2 & 1.2 & 1.2 & 1.2 & 1.2 & 1.2 \\
\hline
\end{tabular}




\begin{tabular}{|c|c|c|c|c|c|c|c|}
\hline MSS & 0.8 & 0.8 & 0.8 & 0.8 & 0.8 & 0.8 & 0.8 \\
\hline PVA (\%) & 2.0 & 1.9 & 1.8 & 1.7 & 1.6 & 1.5 & 1.0 \\
\hline PET (\%) & --- & 0.1 & 0.2 & 0.3 & 0.4 & 0.5 & 0.5 \\
\hline MSE (\%) & --- & --- & --- & --- & --- & --- & 0.5 \\
\hline w/b & 0.27 & 0.27 & 0.27 & 0.27 & 0.27 & 0.27 & 0.27 \\
\hline SP (\%) & 0.45 & 0.45 & 0.45 & 0.45 & 0.45 & 0.45 & 0.45 \\
\hline
\end{tabular}

\section{Sample Preparations and Methods}

For making the cement matrix, mixer type and its rotation speed, mixing procedure and temperature are very important. In present research work electric type mortar mixture was used to prepare the cement matrix as shown in Figure 3. Firstly, all powdered constituents including OPC, GGBFS and MSS were mixed at low speed for approximately 2 to $3 \mathrm{~min}$. Then two-third of water and SP was added into the dry mixture and rotated the mixer for another 2 to $3 \mathrm{~min}$. Then remaining water and SP were added and mixed for 1 to $2 \mathrm{~min}$ to produce consistent and uniform mix. At last, fibers were dispersed slowly into the mixture and rotated until uniform mix was not achieved. To provide the required shape, uniform mix was poured into plates, prisms, and cubes of dimensions $250 \mathrm{~mm} \times$ $250 \mathrm{~mm} \times 75 \mathrm{~mm}, 500 \mathrm{~mm} \times 100 \mathrm{~mm} \times 100 \mathrm{~mm}$ and $70.6 \mathrm{~mm} \times 70.6 \mathrm{~mm} \times 70.6 \mathrm{~mm}$ and placed inside the laboratory for 24 hours. All casted specimens were demoulded after $24 \mathrm{~h}$ and immersed into the water tank for curing. Plates, prisms and cubes specimens were taken out from water tank after $90 \mathrm{~d}, 180 \mathrm{~d}$, and $365 \mathrm{~d}$ to assess the air permeability and sorptivity index, flexural performance and electrical resistivity.

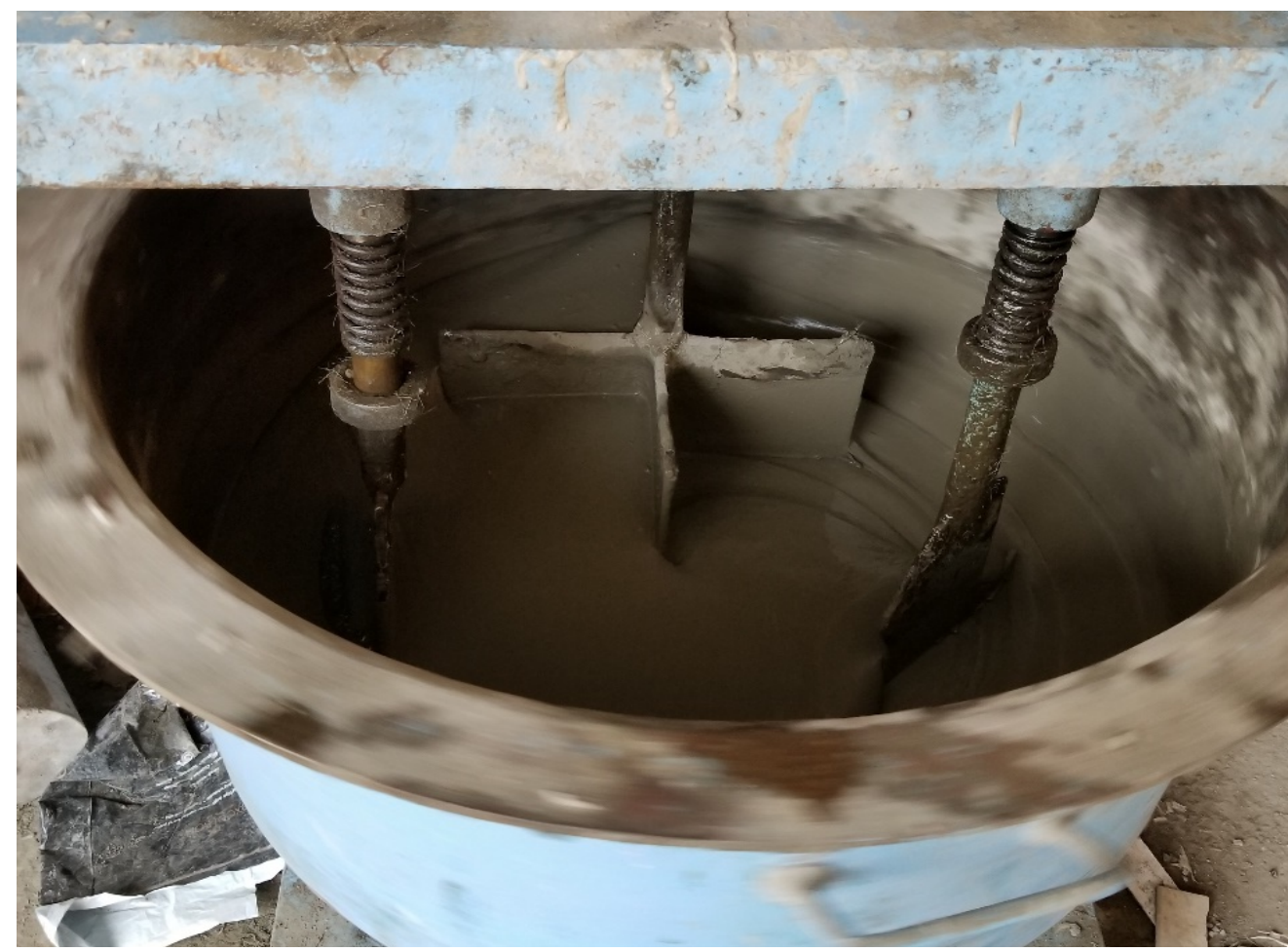

Figure 3. Pictorial view of mortar mixer during mixing. 


\section{TEST METHODS}

\section{Flexural Response}

Prism specimens as shown in Figure 4 were used to assess the flexural performance of various matrix proportions. Four-point bending test was performed to evaluate the load-deflection performance as per IS 516:1959, 2006 and BS-EN-12390-5, 2009 specifications.

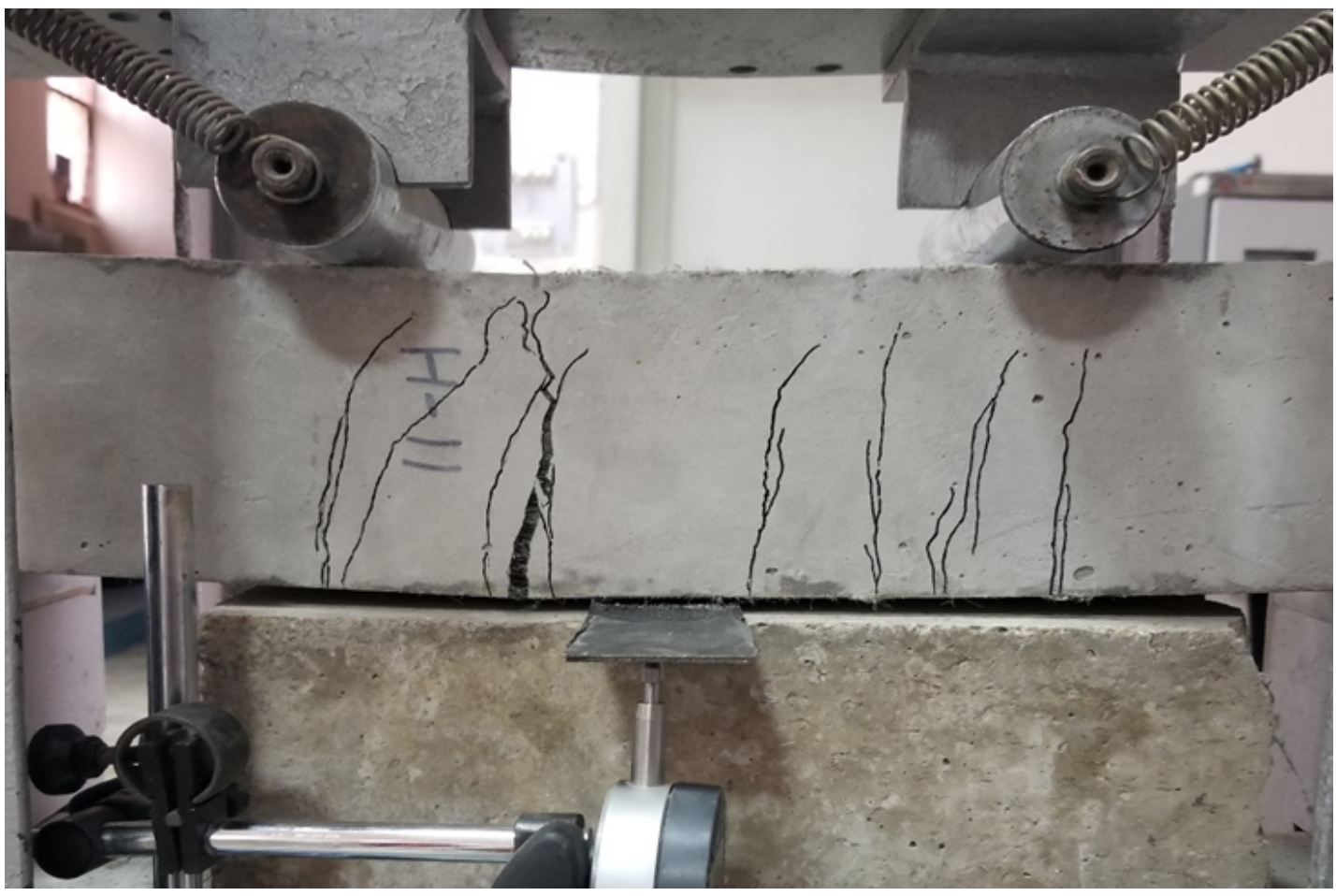

Figure 4. Four-point bending test setup.

\section{Electrical Resistivity (ER)}

ER performance can be used as durability indicator of cementitious material, which represents the movement and diffusion of ions inside the matrix. It is non-destructive technique and can be measured with various methods and indicates corrosion risk and chloride ion penetration into the matrix. In this research work the ER was measured on cubes specimens via a two-point method as shown in Figure 5. The ER $(\rho)$ of the ECC matrix cubes was calculated by the following equation.

$$
\rho=\mathrm{R} \frac{A}{L} k \Omega-c m
$$

where $\mathrm{A}$ is the area of the specimen $\left(\mathrm{cm}^{2}\right), \mathrm{L}$ is the height of the specimen, and $\mathrm{R}(k \Omega)$ is the resistance of the specimen i.e. obtained from the multimeter. The recommended values for the correlation between ER, corrosion risk (CR) and chloride ion penetration have been given in Table 4. 


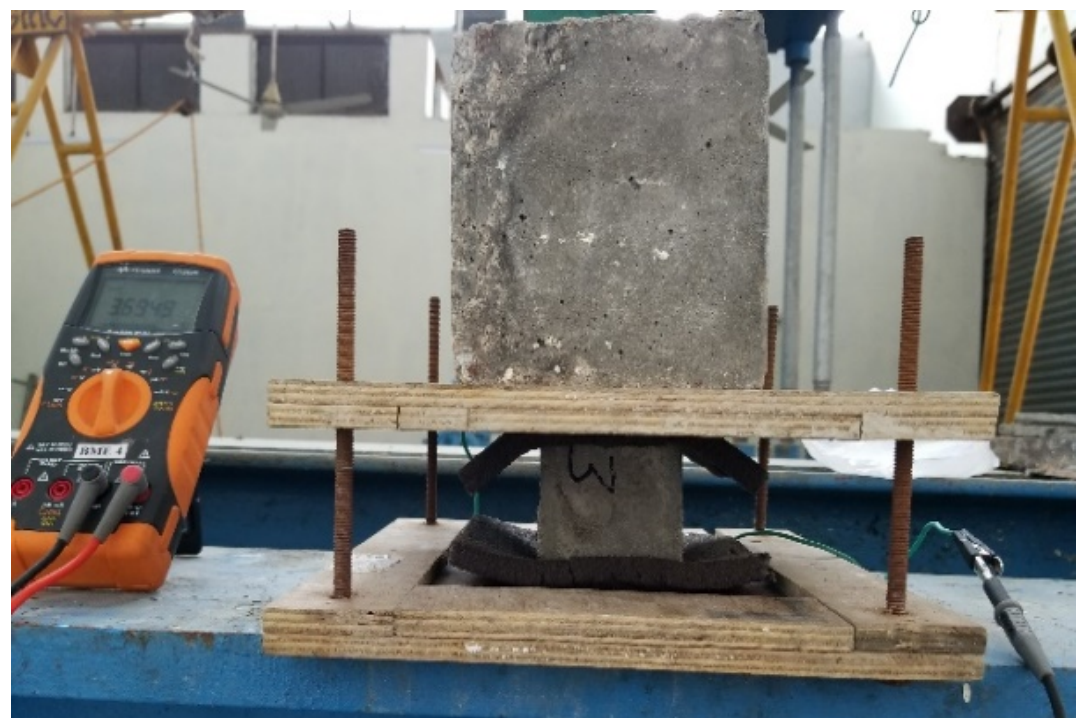

Figure 5. Electrical resistivity setup.

Table 4. Correlation between ER, CR, and CIP (AASTHO T358-15,2015; ACI 222R-01,2010).

\begin{tabular}{|c|c|c|c|}
\hline $\operatorname{ER}(\mathbf{k} \Omega-\mathrm{cm})$ & CIP & ER $(\mathrm{k} \Omega-\mathrm{cm})$ & CR \\
\hline$<12$ & High & $<5$ & Very High \\
\hline $12-21$ & Moderate & $5-10$ & High \\
\hline 21-37 & Low & $10-20$ & Low to moderate \\
\hline $37-254$ & Very Low & $>20$ & Negligible \\
\hline$>254$ & Negligible & --- & --- \\
\hline
\end{tabular}

\section{Air Permeability and Sorptivity (water absorption)}

Movement and diffusion of ions due to porosity is an excellent durability indicator of cement products and related to air permeability and sorptivity (water absorption). Air permeability and sorptivity (water absorption) tests were conducted on plates by using Autoclam permeability system, created by Queen's University, Belfast (United Kingdom). It is a non-destructive technique and also can be used on site for quality control. The assembly of Autoclam system comprises of (a) Base ring, (b) Autoclam body, and (c) electronic controller. The test setup of Autoclam permeability system was used to carry out the air permeability and sorptivity has been shown in Figure 6 . In this investigation, the surface of the casted plates was isolated by taking standard base ring. To commence the air permeability test, the pressure was applied manually inside the Autoclam body with the syringe attached to the system. Test commenced automatically when desired pressure (500 mbar) reached, into the system and then decay in pressure was recorded for the next 15 minutes. The line of natural logarithm of measured pressure against time was plotted by regression, and the slope of the regressed line between $5^{\text {th }}$ minute and $15^{\text {th }}$ minute has been reported as the air permeability index (API) in units of Ln (mbar)/min. The scientific agency (Amphora) on the basis of API gives the criteria to classify the protective quality of cement-based products as presented in Table 5. 
Table 5. API based criteria for protective quality of cement-based products (Autoclam manual, 1994).

\begin{tabular}{|c|c|}
\hline Autoclam API, Ln (mbar) $/$ min & Protective quality \\
\hline$>0.9$ & Very poor \\
\hline$>0.5 \leq 0.9$ & Poor \\
\hline$>0.1 \leq 0.5$ & Good \\
\hline$\leq 0.1$ & Very Good \\
\hline
\end{tabular}

Sorptivity test (water absorption) was also conducted by the Autoclam permeability system, after the two hours of air permeability test completion at same location of specimens. The setup for sorptivity test was similar to that of air permeability test, but the upper channel of Autoclam body was filled with water. Internal priming pump of Autoclam body filled the test area with water and air escaped through bleed tube. After the selected test area was filled with water, priming pump automatically switched off and the micropump maintained the nominal pressure of 20 mbar and then sorptivity test started. The volume of water entering in specimen was recorded every minute for the next 15 minutes duration of test.

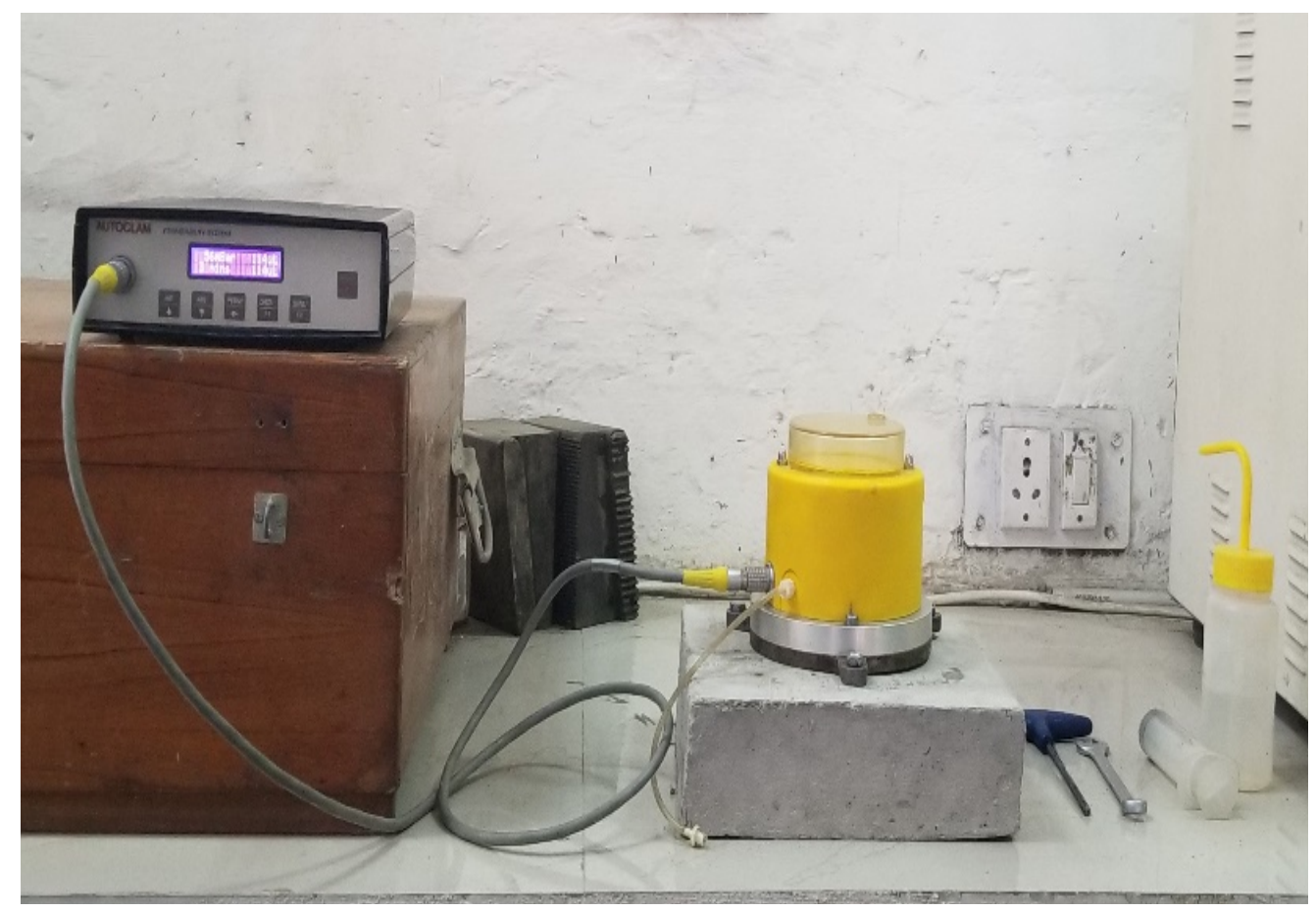

Figure 6. Test setup of Autoclam permeability system. 
A plot of the amount of water entering against square root of time was plotted. The slope of plotted graph reported the sorptivity index in units of $\mathrm{m}^{3} \times 10^{-7} / \mathrm{min}^{1 / 2}$. The criteria to classify the protective quality of cement mixes based-on sorptivity index has been given in Table 6 .

Table 6. Sorptivity based criteria for protective quality of cement-based products (Autoclam manual, 1994).

\begin{tabular}{|c|c|}
\hline Autoclam sorptivity index,$\left(\mathrm{m}^{3} \times 10^{-7} / \mathrm{min}^{1 / 2}\right)$ & Protective quality \\
\hline$>3.40$ & Very poor \\
\hline$>2.60 \leq 3.40$ & Poor \\
\hline$>1.30 \leq 2.60$ & Good \\
\hline$\leq 1.30$ & Very Good \\
\hline
\end{tabular}

\section{Flexural Performance}

\section{OUTCOMES AND DISCUSSION}

The hybridizing impact of microfibers on the flexural performance of ECC matrix has been illustrated in Figure 7(a-c). Flexural strength capacity of ECC prisms ranges from 11.98 to $14.44 \mathrm{MPa}$ and mid span deflection ranges from 4.68 to $6.28 \mathrm{~mm}$ between the ages of 90 to 365 days (d) depending on the various combinations of microfibers.

\section{Hybridization of PVA and PET Fiber}

Hybridization of PVA and PET fiber is a combination of high modulus and low modulus polymeric state fibers. Amalgam of these two fibers strongly influenced the flexural performance of ECC mixture. The literature of cementitious composite witnessed that low and high modulus fiber exhibited excellent behavior with several tiny cracks and also helps in minimizing the cost of fiber reinforced matrix (Pakravan et al., 2016 \& Li et al., 2016). Subrogation of PVA with PET fiber at dosage 5\%, 10\%, 15\%, 20\%, and 25\% enhanced the mid span defection capacity by $3.61 \%, 7.63 \%, 10.84 \%, 17.26 \%$ and $23.69 \% ; 6.15 \%, 11.30 \%, 14.28 \%, 20.83 \%$ and $24.60 \% ; 4.16 \%$, $7.53 \%, 11.90 \%, 18.25 \%$ and $22.02 \%$ after $90 \mathrm{~d} ; 180 \mathrm{~d} ; 365 \mathrm{~d}$ water curing. Flexural strength capacity of HS2 and HS3 mix proportions nearly similar to HS1 mix proportion. Increment in quantity of PET as PVA fiber subrogation decreased the flexural strength; but, increased the mid span deflection capacity. Flexural strength of HS4, HS5, HS6 mix proportion was decreased by $6.02 \%, 10.02 \%, 14.18 \% ; 5.03 \%, 7.51 \%, 10.49 \% ; 6.13 \%, 8.65 \%, 12.26 \%$ after $90 \mathrm{~d}$; 180d; 365d curing period as compared to HS1 mix proportion. Decrement in the flexural strength of PET fiber blended mix proportions was observed due to low modulus of PET as compared to PVA fiber, which reduced the fiber bridging strength in the matrix. On the other hand, deflection capacity of ECC matrix improved with PVA and PET fiber hybridization, better elongation capacity, slip hardening behavior, chemical bonding between PET fiber and cement matrix was responsible for this enhancement. Because the nature of PVA fiber is hydrophilic, which sustain a strong chemical bond between fiber and matrix i.e. responsible for fibers rupture than pull out. PET fiber lies in the middle state of hydrophobic or hydrophilic, which helps to sustain a very good bond between matrix and fiber surface (Rathod et al., 2010). This wacky nature of PET fiber contributes in the high absorption capacity and slip hardening behavior, which promote the ductile nature of the ECC. Minimum flexural strength was found 11.98 Mpa with 25\% subrogation of PVA with PET fiber which is similar to fly ash PVA-ECC mixture (Pan et al., 2015 \& Zhigang et al., 2014). The $25 \%$ utilization of PET fiber in ECC matrix as PVA fiber replacement reduced the total cost of ECC matrix by $20.72 \%$ for one cubic meter, which promote the use of ECC in developing countries or on large scale. 


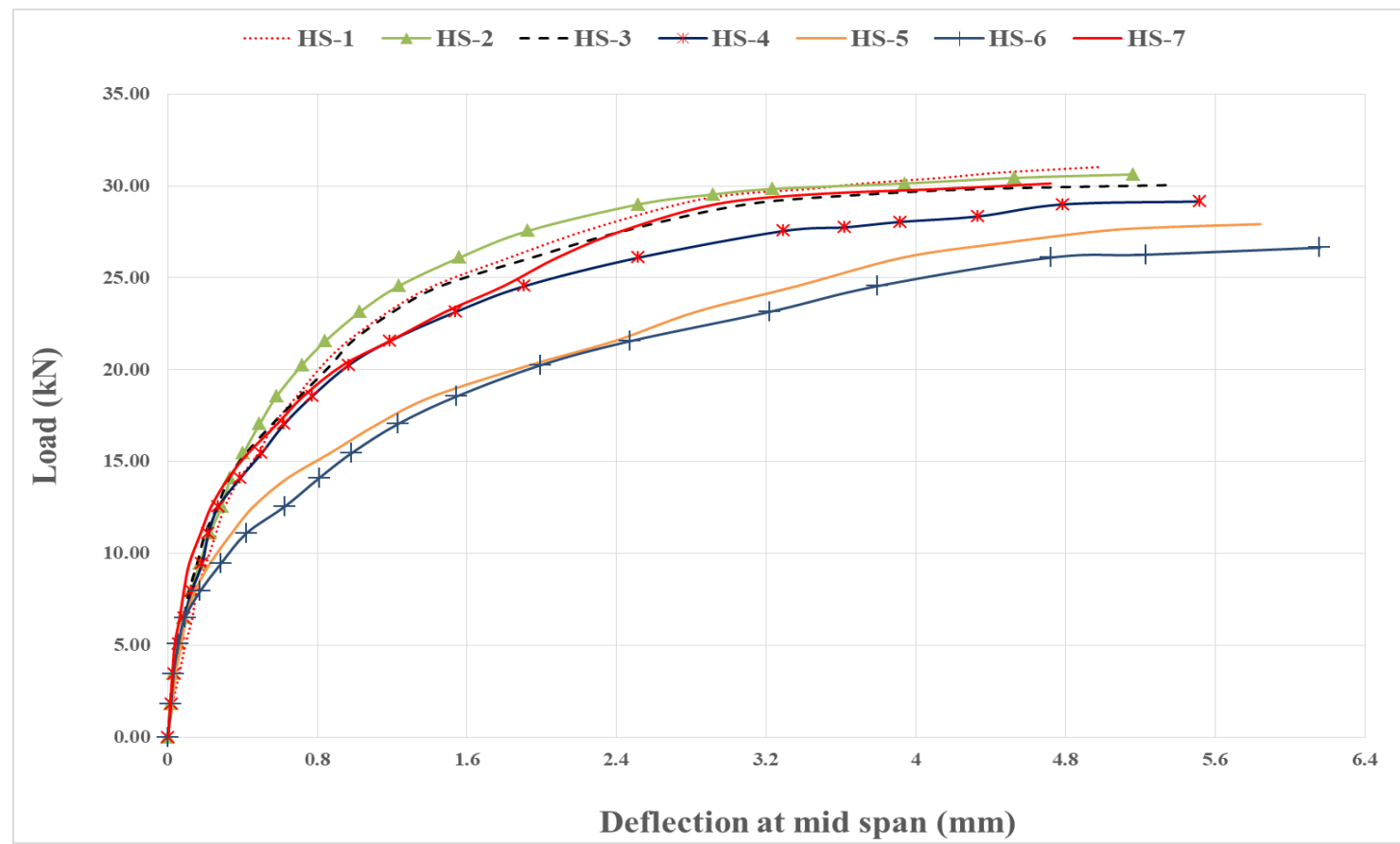

Figure 7 (a). Load deflection response of various mixes after 90d.

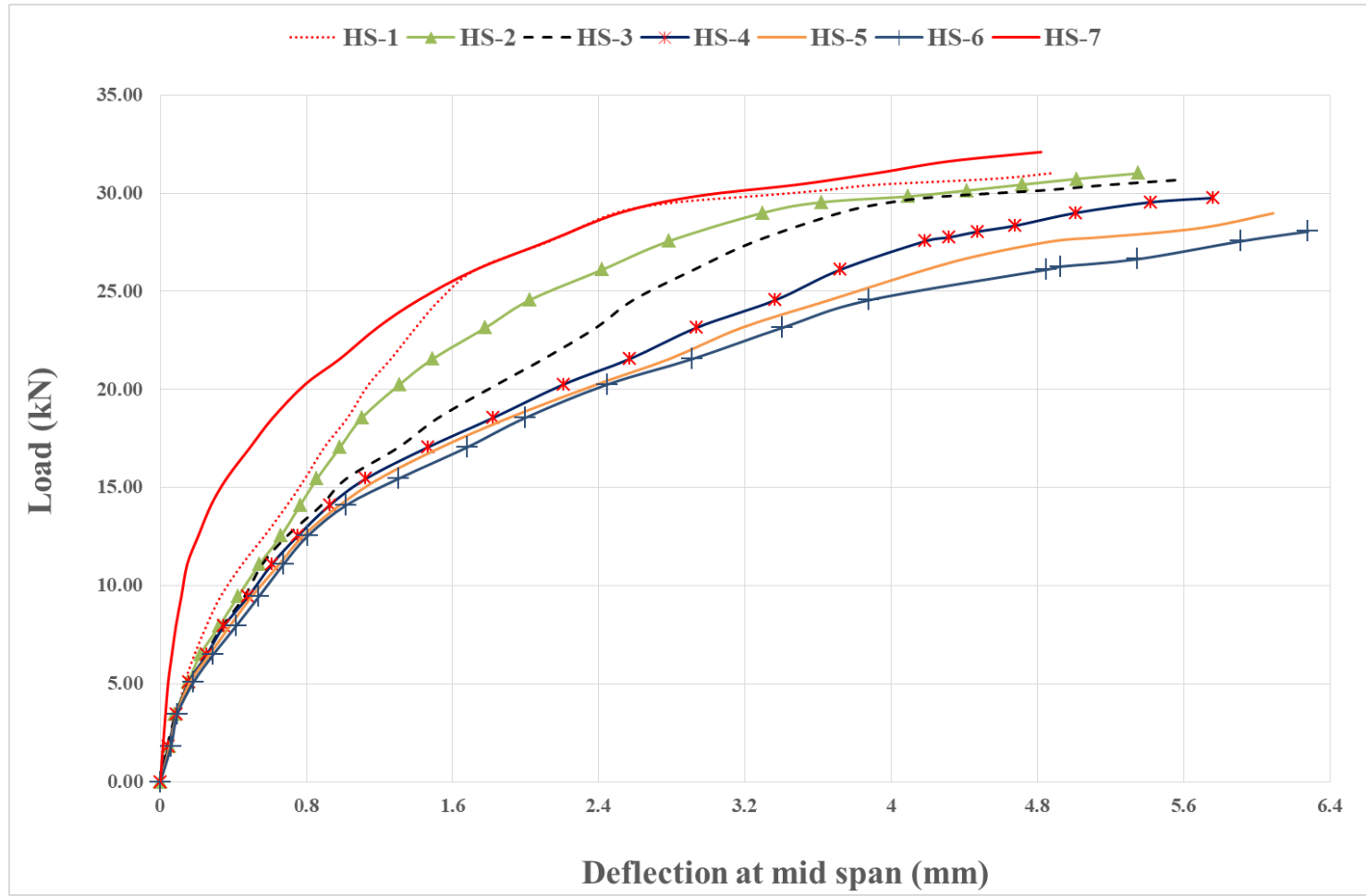

Figure 7 (b). Load deflection response of various mixes after 180d. 


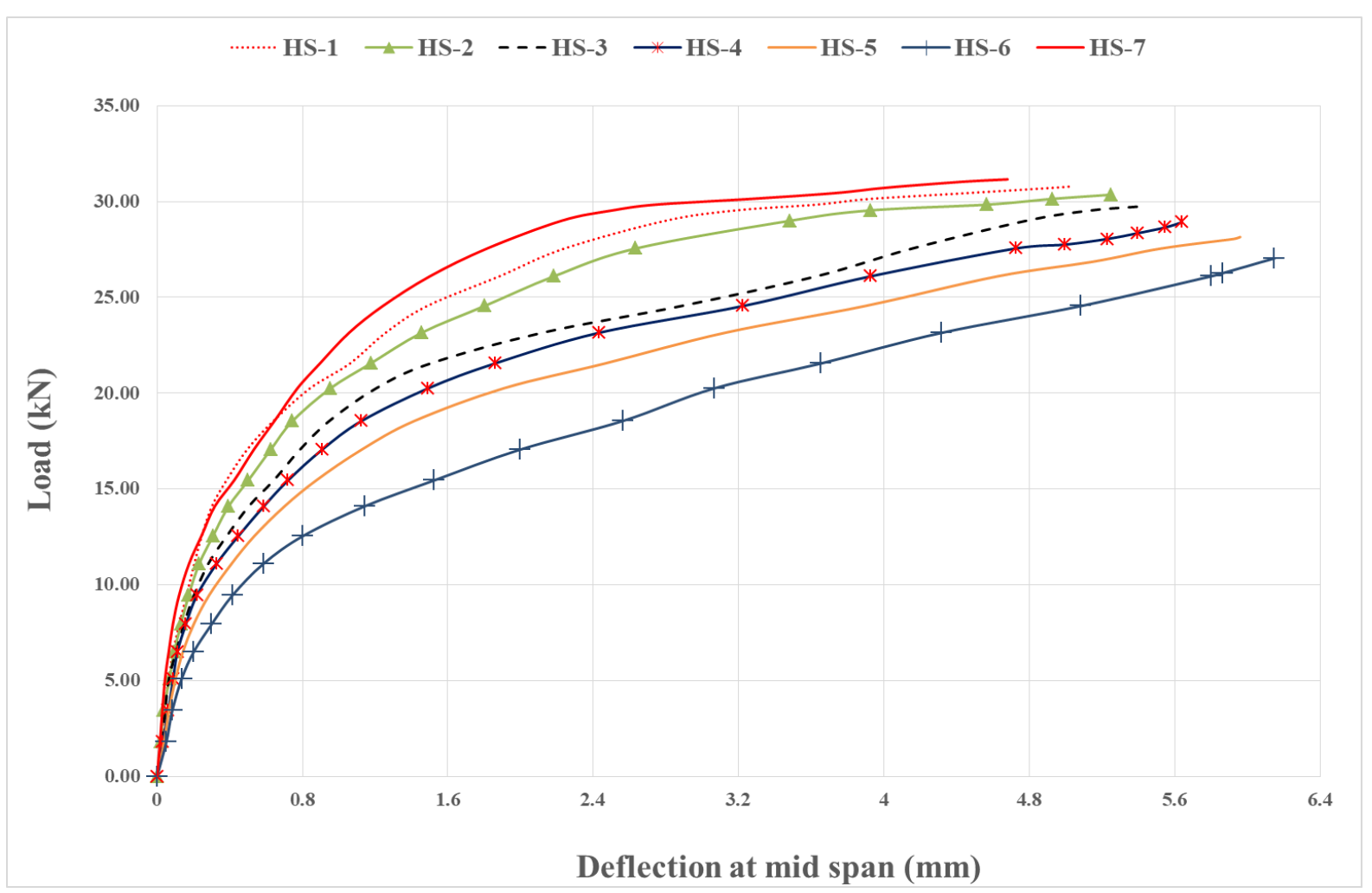

Figure 7 (c). Load deflection response of various mixes after 365d.

\section{Hybridization of PVA, PET, and MSE Fiber}

After the successful intrusion of PET fiber in ECC, further research work was carried out on combination of PVA, PET and MSE fiber at dosage of 50\%, 25\%, and 25\%, respectively of the total fiber volume fraction. The PVA and MSE fibers used in this work lie in high modulus class, whereas PET fiber lies in the low modulus class. Previous research works reported that the hybridization of steel and PVA fiber exhibited excellent performance in terms of strength as well as strain parameters (Soe et al., 2013 ${ }^{\mathrm{a}}$ \& Soe et al., 2013 ${ }^{\mathrm{b}}$; Alhmead et al., 2003). In the present work aim was to reduce the cost of ECC with acceptable limit of various parameters by using PVA, MSE and PET fibers in combination. Amalgam of these three fibers not significantly affect the flexural strength of the matrix; whereas, mid span defection capacity decreased up to $7.14 \%$ as compared to HS1 mix proportion. In comparison to HS6 mix proportion the flexural strength of HS7 mix proportion enhanced by $15.30 \%$ and deflection capacity decreased by $23.90 \%$. after final curing. Deflection capacity of all hybrid mix proportions developed in the opposite order of their flexural strength. MSE fiber sustain a perfect bond with matrix which was responsible for fiber rupture than pull out during loading, due to this the deflection capacity found to be reduced. On the other hand, high modulus of MSE fiber provided higher bridging strength during loading, which enhanced the flexural strength of the ECC prisms. Fiber bridging action and multiple microcracking behaviour of some prism specimens have been shown in Figure 8. Minimum flexural strength and mid span deflection was found $13.56 \mathrm{MPa}$ and $4.68 \mathrm{~mm}$ in $\mathrm{HS} 7 \mathrm{mix}$ proportion which was similar to other related works of PVA-ECC (Pakravan et al., 2016; Meng et al., 2017; Soe et al., $2013^{\mathrm{a}}$ ). Therefore, the hybridization of PVA, PET and MSE fibers at dosage of 50\%, 25\% and 25\% reduced the total cost of the ECC by $42.37 \%$ for one cubic meter without affecting the flexural performance. 


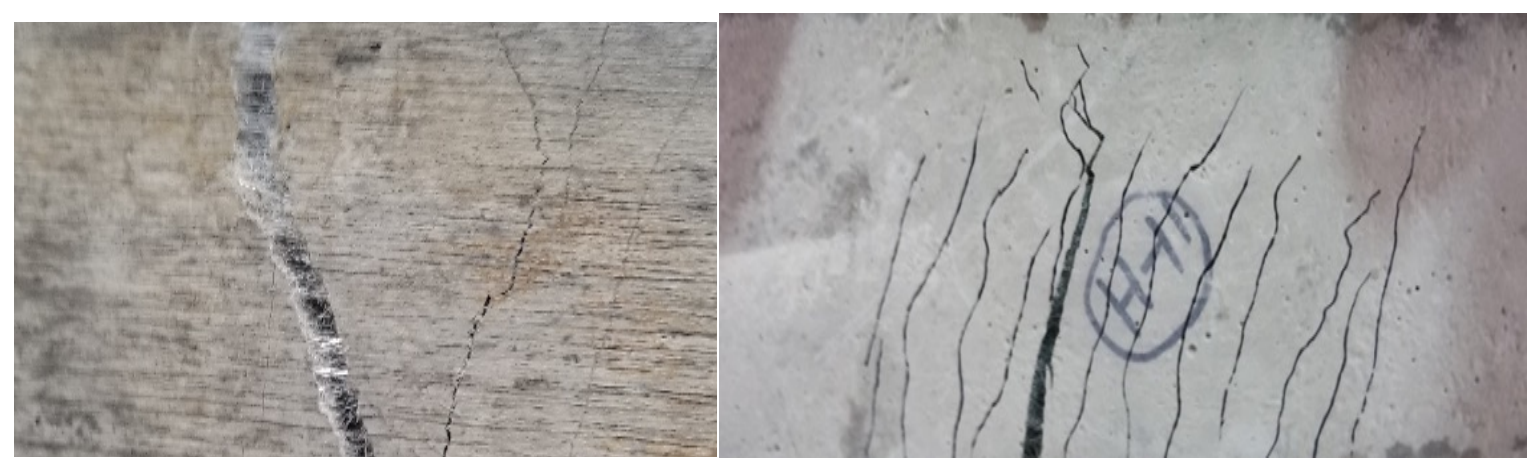

Figure 8. Zoomed view of fiber bridging and multiple microcracks on prism specimens.

\section{Electrical Resistivity}

Electrical performance (resistivity or its reciprocal) of cement matrix has been utilized as a durability indicator, which represents the movement and diffusion of ions through the whole structure of matrix (Tsung et al., 2017; Ronaldo et al., 2016). The impact of various fiber combinations on ER performance has been shown in Figure 9. ER for all mix proportions ranges from $61.98 \mathrm{k} \Omega$-cm to $146.70 \mathrm{k} \Omega$-cm between the ages of 90 and 365 days (d) depending on the type and quantity of microfibers used.

\section{Hybridization of PVA and PET Fiber}

PVA and PET both are polymeric and low conductive nature fibers; however, analysis of their role in cement matrix is very important. To assess the electrical performance of fibers in ECC matrix, the ER with various fiber combinations has been investigated up to one-year curing age. The experimental observations depicted that ER of fully PVA blended mix (HS1) was less than hybrid mixes with PVA and PET fiber. Replacement of PVA with PET fiber at dosage of $5 \%$ and $10 \%$ had no considerable change in ER of cement matrix as compared to HS 1 mix proportion. Increment in the quantity of PET as PVA replacement enhanced the ER of the cement matrix. Inclusion of PET at $15 \%, 20 \%$ and $25 \%$ as PVA replacement increased the ER values of cement matrix by $5.36 \%, 7.93 \%$, $11.75 \%$; $4.12 \%, 5.83 \%, 8.37 \% ; 5.32 \%, 9.18 \%, 12.93 \%$ after $90 \mathrm{~d} ; 180 \mathrm{~d} ; 365 \mathrm{~d}$ water curing respectively. As the electrical conductivity of both the fibers is very low, despite that intrusion of PET fiber in cement matrix revealed better electrical resistivity. The character of PVA fibers was hydrophilic and it was also oil coated by $1.2 \%$ of engine oil used in this study. Presence of PVA fiber in the cementitious mix increased the porosity of the matrix around the fiber transition zone. The presence of pores promotes the movement of ions easily inside the cement matrix which is directly related to electrical performance, permeation, chloride ingress and corrosion. Similarly, Sakulich et al., 2011 \& Suryanto et al., 2018 witnessed that the inclusion of PVA fiber in ECC matrix created the porosity around the fibers transition zone. The PET fibers used in this study had the ability to make a good bond with cement matrix. Inclusion of PET fiber decrease the micropores present on the transition zone of PVA fiber in cement matrix; because, PET fiber does not behave like hydrophobic or hydrophilic. Therefore, the hybridization of PVA fiber and PET fiber in ECC matrix enhanced the ER characteristic and also contributes in making the low cost ECC. 


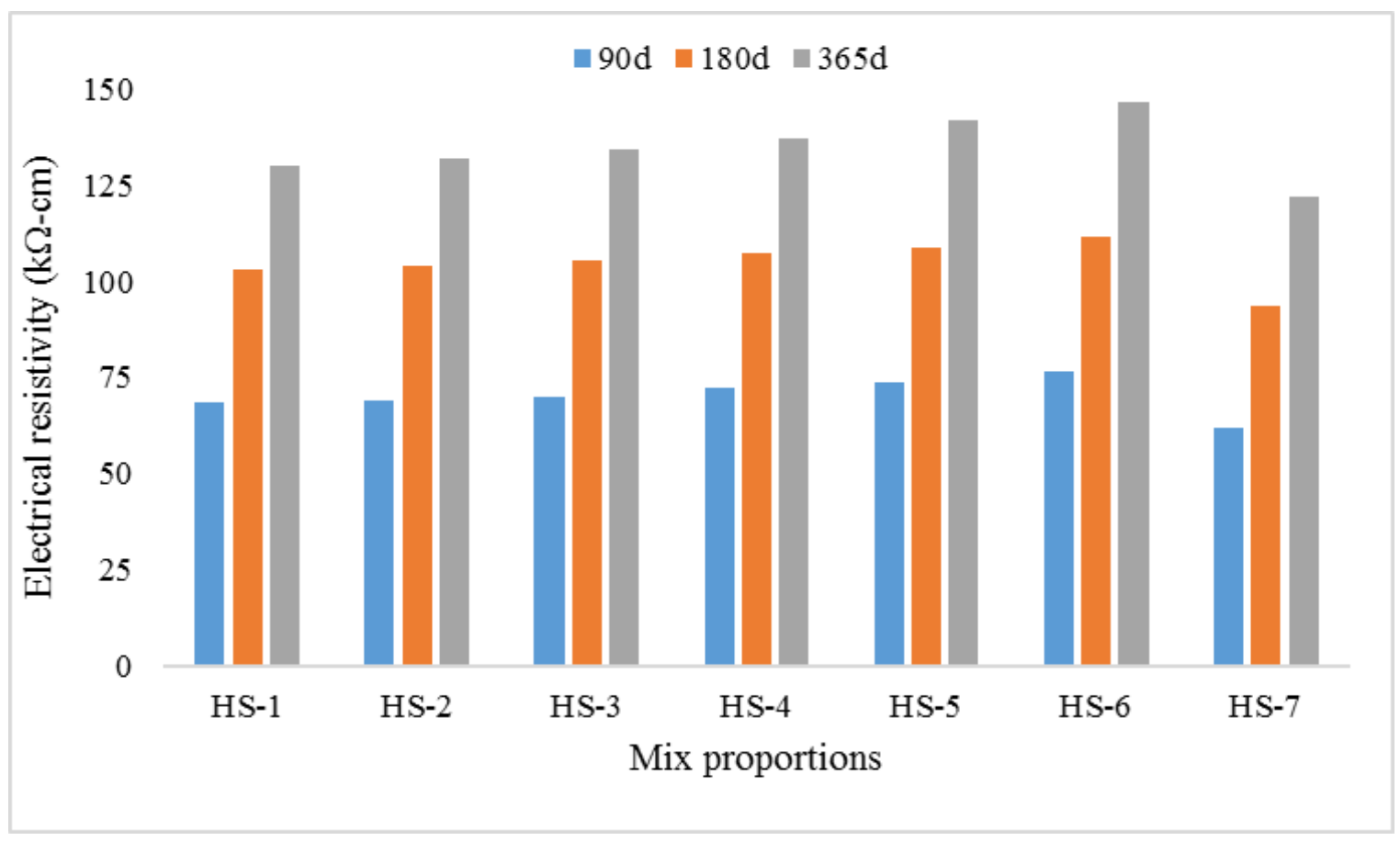

Figure 9. ER Performance of various mixes.

\section{Hybridization of PVA, PET and MSE Fiber}

After the successful utilization of PET fiber up to $25 \%$ as PVA substitution another $25 \%$ was substituted by MSE fiber. Combination of PVA, PET and MSE fiber at dosage of 50\%, 25\% and $25 \%$ of the total fiber volume fraction revealed lower electrical resistivity than HS1 and HS6 mix proportion. ER of HS7 cement matrix proportion decreased by $9.48 \%, 8.79 \%, 6.03 \%$ and $19.01 \%, 15.84 \%, 16.79 \%$ with reference to HS1 and HS6 mix proportion after $90 \mathrm{~d}, 180 \mathrm{~d}$ and $365 \mathrm{~d}$ water curing respectively. Microsteel fiber was conductive in nature due to which the ER of HS7 mix proportion reduced. Numerous researchers reported the intrusion of steel fibers in cementitious mix increased the electrical conductivity of the matrix (Banthia et al., 1992). With increasing the age of curing the change in ER percentage between HS1 and HS7 mix proportion was slightly reduced, it may be due to corrosive nature of steel. Because with increase in the time period the chances of corrosion on steel surface enhanced, which may defer the flow of current up to some limit. The values of ER for all mixes revealed that the chances of chloride ion penetration and corrosion risk were low and negligible for all cementitious matrix used in this research, as discussed in Table 3. Finally, from this non-destructive technique it has been observed that the hybridization of PVA, PET and MSE fiber enhanced the durability performance of ECC matrix with respect to chloride ingress, corrosive effect and electrical performance.

\section{Air Permeability}

To assess the permeation capacity of cement matrix the API was evaluated at the age of $90 \mathrm{~d}, 180 \mathrm{~d}$ and $365 \mathrm{~d}$ with utilization of various fibers in combination and API performance has been illustrated in Figure 10. 


\section{Hybridization of PVA and PET Fiber}

The observed values of API indicated that maximum and minimum air permeability was found in HS1 and HS7 mix proportion respectively. Due to the micropores present around the transition zone of PVA fiber in cement matrix, air permeability was found maximum in HS1 mix proportion. In ECC matrix the inclusion of PET as PVA fiber replacement decreased the API. Combination of PET and PVA fiber at rate of $25 \%$ and $75 \%$ revealed maximum reduction in API as compared to HS1 mix proportion, which was $18.20 \%, 20.37 \%$, and $28.20 \%$ after $90 \mathrm{~d}, 180 \mathrm{~d}$ and $365 \mathrm{~d}$ water curing respectively. The results of API revealed that intrusion of PET fiber in ECC matrix reduced the percentage of micropores as compared to the pores present in HS1 mix proportion. Reduction in porosity impaired the movement of ions through the whole structure of the ECC matrix, which was responsible for better air permeability performance of HS6 as compared to HS1 mix proportion. The continuation of hydration process of ECC matrix decreased the API values with increase in the time period. Numerous researchers witnessed that API decreased with increase in the water curing age (Pan et al., 2016). Therefore, the hybridization of PVA fiber and PET fiber in ECC matrix enhanced the API characteristic and also promote ECC matrix for sustainability.

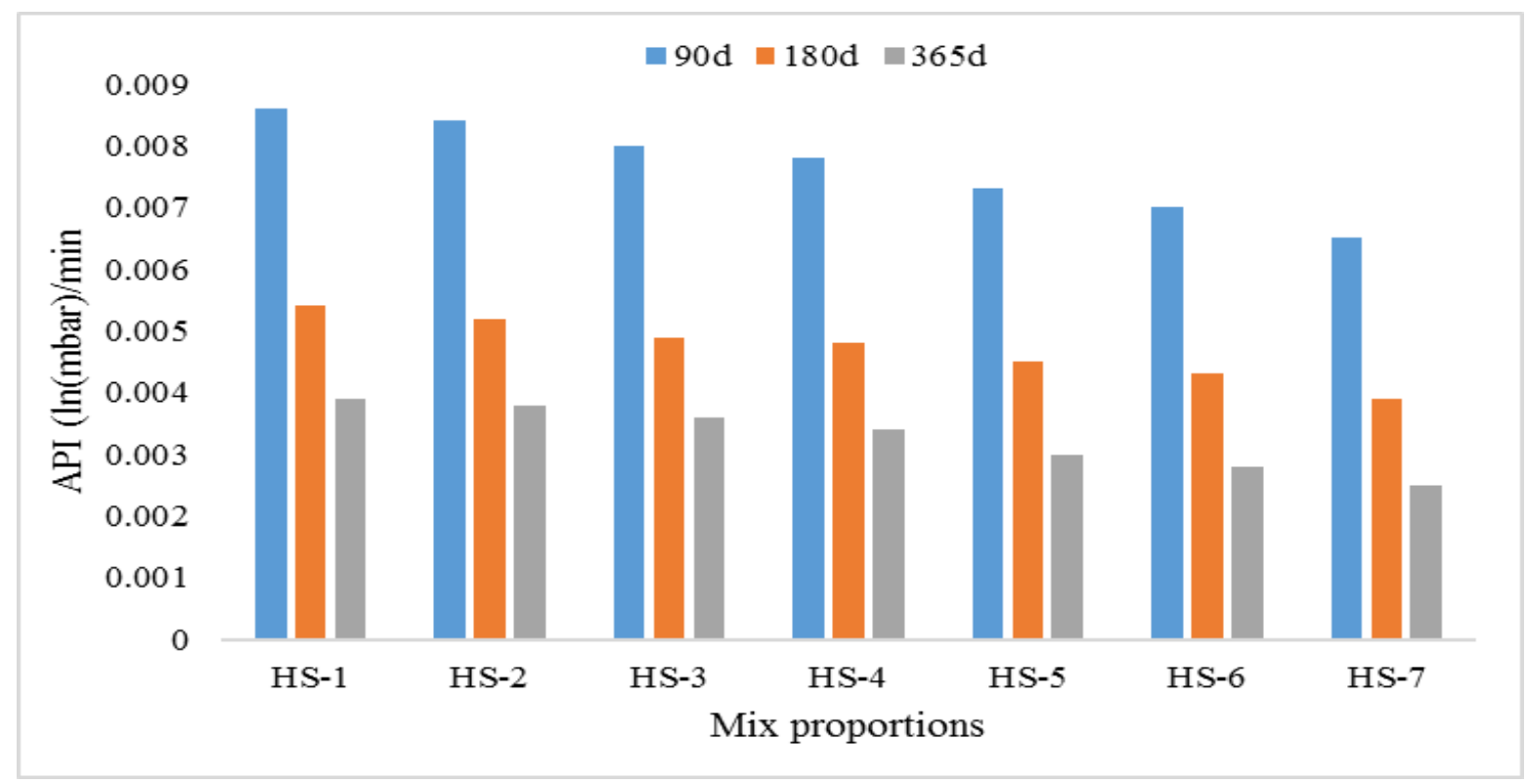

Figure 10. Air permeability index of various mixes.

\section{Hybridization of PVA, PET and MSE Fiber}

The assessed values of API depicted that air permeability of ECC matrix reduced with inclusion of PVA, PET and MSE fiber (at 50\%, 25\% and 25\%) in hybridization. API of HS7 mix proportion reduced by $24.41 \%, 27.77 \%$, $35.89 \%$, and $7.14 \%, 9.30 \%, 10.71 \%$ as compared to HS1 and HS6 mix proportion after $90 \mathrm{~d}, 180 \mathrm{~d}, 365 \mathrm{~d}$ time period respectively. Sticking of MSE fiber and matrix make a strong bond between them. Also, the bond between MSE fiber and matrix near the transition zone is strong, which results into reduction of micropores. Thus, the perfect bonding and packaging of particles with MSE fiber reduced the percentage of micropores present in ECC matrix, which was responsible for diffusion of ion through cementitious composite. The observed values of API range from 0.0086 to $0.0025 \mathrm{Ln}(\mathrm{mbar}) / \mathrm{min}$ for all the mix proportions at various curing ages. According to the criteria for assessing the quality of cement matrix based on API as presented in Table 4, the quality of all ECC mixes was "very good" against 
air permeability. Finally, the combination of all three fibers (PVA, PET and MSE) reduced the air permeability of ECC matrix and contribute in making durable cement matrix.

\section{Sorptivity (water absorption)}

To assess the water absorption capacity of cement matrix the sorptivity index was evaluated at the age of $90 \mathrm{~d}$, $180 \mathrm{~d}$ and $365 \mathrm{~d}$ with combination of PVA, PET and MSE fibers and performance of all mixes has been illustrated in Figure 11.

\section{Hybridization of PVA and PET Fiber}

Maximum and minimum absorption capacity was found in HS1 and HS6 mix proportion. Inclusion of PET as PVA replacement reduced the water absorption capacity of ECC matrix. Hybridization of PVA and PET fiber marginally decreased the sorptivity index, the highest reduction was found as $14.64 \%, 19.40 \%$ and $16.23 \%$ after $90 \mathrm{~d}$, $180 \mathrm{~d}$ and $365 \mathrm{~d}$ curing respectively in HS6 mix proportion. As nature of both the fibers was same (polymeric), but with the inclusion of PVA alone and combination of PET and PVA in ECC matrix variation in values of various properties was observed. Grouping of PVA fiber revealed that presence of hydroxyl groups in large numbers made the nature of PVA fiber hydrophilic, which limits the water barrier properties of it. And as discussed earlier the utilization of PVA fiber in ECC matrix enhanced the porosity around the transition zone of fibers. All these properties and behavior of PVA fibers increases the chances of water absorption in HS1 mix proportion as compared to other compositions used in this research work (Redon et al., 2001; Sakulich et al., 2011 \& Suryanto et al., 2018). Numerous researchers reported that the nature of PET fiber is hydrophobic, and it is water repellent material (Rathod et al., 2010 \& U.S Patent, 1977). Due to these properties of the PET fiber, reduction in sorptivity index values of ECC matrix was observed. Therefore, the hybridization of PVA and PET fiber in ECC matrix contribute in the reduction of sorptivity index.

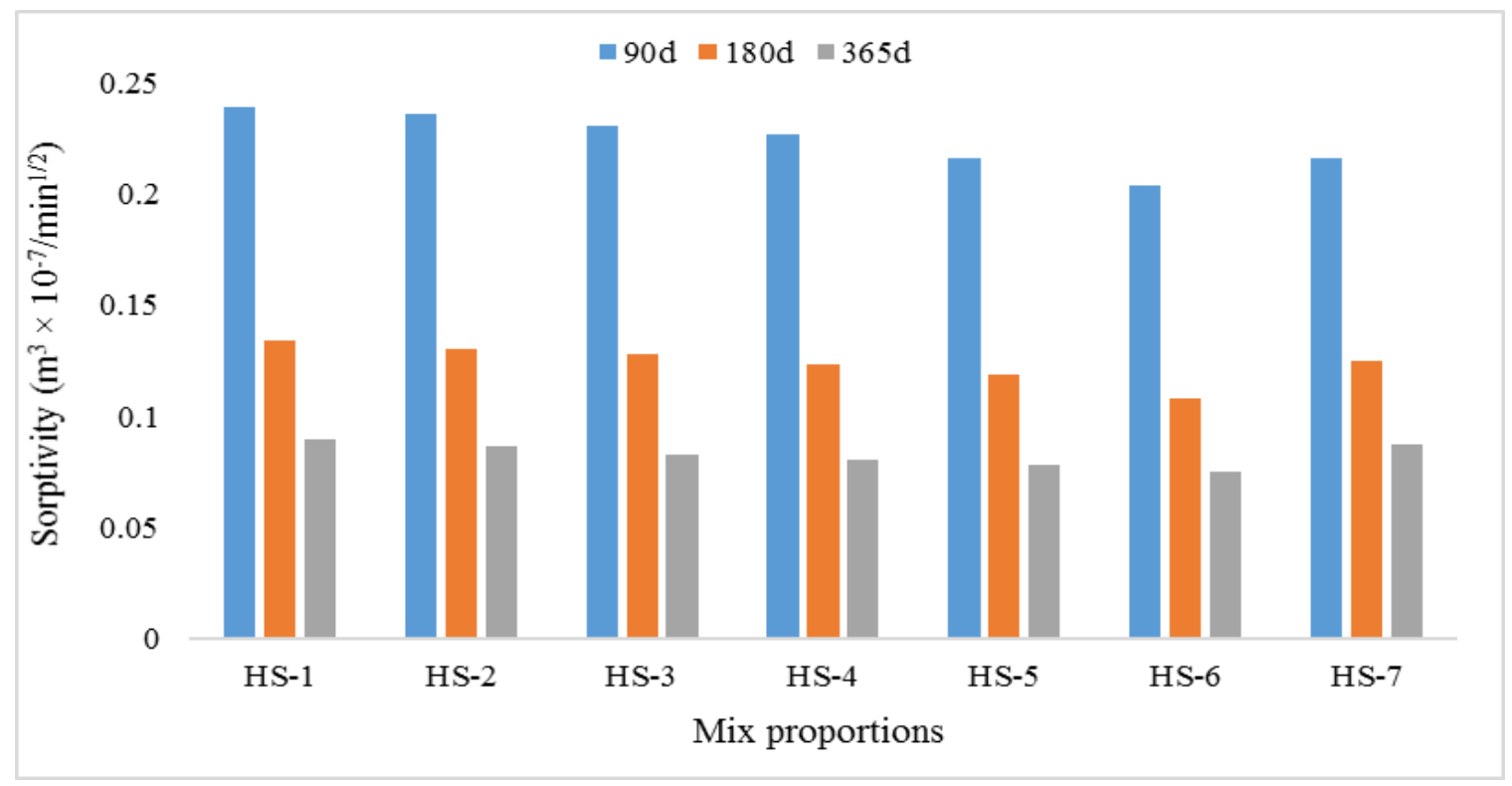

Figure 11. Sorptivity (water absorption) index of various mixes. 


\section{Hybridization of PVA, PET and MSE Fiber}

The assessed values of sorptivity index depicted that water absorption of ECC matrix reduced with inclusion of PVA, PET, and MSE fiber (at 50\%, 25\% and 25\%) in hybridization. Sorptivity index of HS7 mix proportion reduced by $9.63 \%, 6.71 \%$ and $2.35 \%$, as compared to HS1 mix proportion after $90 \mathrm{~d}, 180 \mathrm{~d}, 365 \mathrm{~d}$ curing time period respectively. Cement matrix behaves sticky and makes a strong bond with cementitious products due to presence of MSE fibers, which promote the diffusivity of ions in whole structure. The observed values of sorptivity ranges from $0.239 \mathrm{~m}^{3} \times 10^{-7} / \mathrm{min}^{1 / 2}$ to $0.0748 \mathrm{~m}^{3} \times 10^{-7} / \mathrm{min}^{1 / 2}$ for all the mix proportions at various curing ages. The values of sorptivity index for all the mixes was found less than $1.30 \mathrm{~m}^{3} \times 10^{-7} / \mathrm{min}^{1 / 2}$, which demonstrate "very good" quality of ECC matrix against water absorption as per criteria given in Table 5. At the end, combination of all three fibers (PVA, PET and steel) reduced the water absorption (sorptivity) and promote the use of ECC matrix in hydraulic structures.

\section{FINAL REMARKS}

Sustainability of any material depends on the durability performance, energy and resources consumption, cost and life span of the material. As, the cement based construction materials consume energy and natural resources in lots of quantity and sometimes in harsh environmental conditions the durability performance of concrete structures is also affected. Recent scenario of making concrete structures revealed that the cost of the cement-based matrix increased with the enhancing quality. In the composition of reinforced concrete, aggregates, cement and steel are the basic raw materials. The manufacturing of these materials consumes natural resources and energy in very high quantity and the processing of these materials also extract various types of wastes which impact the environment. Therefore, all these things discussed above are very important in the composition of any material. In the present investigation 55\% (of the total cementitious material) GGBFS (iron industry waste) and non-degradable plastic-based fibers (PVA and PET) have been utilized. The inclusion of GGBFS and fibers help in conserving the natural resources, contribute in making of eco-friendly sustainable cementitious product. Results obtained from present investigation revealed that the hybridization of fibers enhanced the mechanical and durability performance (enhance the life span) and also reduced the cost of cement matrix up to $42.37 \%$ for one cubic meter. Utilization of waste, lower cost and better performance of new formed cement matrix possesses very high sustainability, which promote the use of this material on large scale structural applications.

\section{CONCLUSION}

In the present investigation, the performance of ECC matrix with inclusion of microfibers (PVA, PET, and MSE) in hybridization has been carried out. Hybridizing effect of fibers was investigated through flexural strength, deflection capacity, electrical resistivity, air permeability, and sorptivity characteristics. The main conclusions from this experimental investigation can be summarized as follows:

\section{Hybridization of PVA and PET Fiber}

- Inclusion of 25\% PET fiber as PVA replacement decreased the flexural strength of ECC matrix up to $14.18 \%$. Low modulus of PET fiber diminished the fiber bridging strength which attributed to reduction in flexural strength of ECC matrix. 
- The optimum deflection capacity was found in HS6 mix proportion $24.60 \%$ higher than HS1. Low modulus fibers can absorb high energy, which was responsible for better deflection capacity in HS6 mix proportion than other mixes. Finally, combination of PVA and PET fiber enhanced the ductile nature of ECC matrix.

- Optimum ER was found in HS6 mix proportion 12.93\% higher than HS1 mix. Electrical conductivity of both the fibers was very low despite that the ER performance increased. PVA fibers are hydrophilic in nature due to which the percentage of micropores increased at the transition zone of fibers which promote the easy flow of the ions in the matrix structure. On the other hand, the PET fibers hydrophobic in nature, were able to reduce the micropores percentage in matrix due to better bonding between fiber and matrix.

- With the hybridization of PVA and PET, the maximum reduction in air permeability (28.20\%) and water absorption (19.40\%) was observed in HS6 mix proportion in comparison to mix. PET fibers are hydrophobic in nature, then inclusion reduced the water absorption capacity in ECC matrix.

- Finally, hybridization of PVA and PET not only enhanced the unique characteristics of ECC, but also reduced the cost of ECC up to $20.72 \%$.

\section{Hybridization of PVA, PET, and MSE Fiber}

- The optimum flexural strength of ECC matrix was found with the inclusion of PVA, PET and MSE in combination. Hybridization of all three fibers enhanced flexural strength by $2.86 \%$ and $15.30 \%$ as compared to HS1 and HS6 mix proportion. The physical nature of MSE fiber i.e. high modulus, provide excellent fiber bridging strength with matrix which was responsible for increment in flexural strength of HS7 mix proportion.

- Deflection capacity, ER and API of HS7 mix proportion decreased by $7.14 \%, 9.48 \%$ and $35.9 \%$ as compared to HS1 mix proportion. MSE fiber was able to make a perfect bond due to sticking behavior with matrix. Due to the strong bonding, fibers ruptured than pullout. Packaging of the matrix particles at fiber surface was responsible for reduction in deflection capacity and API. The MSE fibers are conductive in nature which attributed to the lower ER in HS7 mix.

- The particle packaging behavior of MSE with matrix diffused the movement of ions in cement matrix which attributed lesser water absorption capacity (9.62\%) of HS7 mix proportion than HS1 mix. Hybridization of all three fibers not only enhanced the strength and durability performance; but cut the total cost of ECC up to $42.37 \%$.

Eventually, the present research recommends the use of hybrid ECC matrix in developing countries on large scale construction. The durability examination in this study promote the use of the low cost ECC in hydraulic structures. Low cost, superior performance and inclusion of waste and non-degradable materials in newly formed ECC matrix possesses high durability and strength properties and also promotes eco-friendly nature of mix.

\section{ACKNOWLEDGMENT}

The authors would like to acknowledge the financial assistance of University Grants Commission, New Delhi.

\section{REFERENCES}

ACI 222R-01, 2010. Protection of metals in concrete against corrosion.

Ahmed, S.F.U., Maalej, M. \& Paramasivam, P. 2003. Strain hardening behaviour of fiber reinforced cement composites. Journal of ferrocement 33: 172-182.

Ali, M.A.E.M., Soliman, A.M. \& Nehdi, M.L. 2017. Hybrid-fiber reinforced engineered cementitious composite under tensile and impact loading. Materials and Design. 117: 139-149. 
Alrefaei, Y., Khaldoun, R. \& Maalej, M. 2018. Shear strength of beams made using hybrid fiber-engineered cementitious composites. Journal of Structural Engineering 144: 04017177.

American Association of State Highway and Transport Officials, AASHTO T358- 15, 2015. Standard Test Method for Surface Resistivity Indication of Concretes Ability to Resist Chloride Ion Penetration. Washington, USA.

Autoclam permeability system operating manual, 1994. Department of civil Engineering, Queen's University, Belfast, U.K.

Banthia, N., Djeridane, S. \& Pigeon M. 1992. Electrical resistivity of carbon and steel micro-fiber reinforced cements. Cement and concrete research 22: 804-814.

BS-EN-12390-5, 2009. Testing hardened concrete, Flexural strength of test specimens. British Standard Institution.

IS 516-1959, 2006. Methods of tests for strength of concrete (18th ed.). Bureau of Indian Standards, New Delhi.

Kim, Y.Y., Kong, H.-J. \& Li, V.C. 2003. Design of engineered cementitious composite suitable for wet-mixture shotcreting. Mater. J. 100: 511-518.

Kong, H.-J., Bike, S.G. \& Li, V.C. 2003. Development of a self-consolidating engineered cementitious composite employing electrosteric dispersion/stabilization. Cement and concrete composites 25: 301-309.

Li, J. \& Yang, E.H. 2017. Macroscopic and micro structural properties of engineered cementitious composites incorporating recycled concrete fines. Cement and Concrete Composites. 78: 33-42.

Li, Q., Zhao, X., Xu, S. \& Gao, X. 2016. Influence of steel fiber on dynamic compressive behavior of hybrid fiber ultra-high toughness cementitious composite at different strain rates. Construction and Building Materials 125: 490-500.

Li, V.C. \& Kanda, T. 1998 ${ }^{\text {a }}$. Engineered cementitious composites for structural applications. J. Materials in civil engineering 10: 66-69.

Li, V.C. 1998 ${ }^{\mathbf{b}}$. Engineered Cementitious Composites - Tailored Composites through Micromechanical Modeling. Fiber Reinforced Concrete: Present and the Future edited by N. Banthia, A. Bentur, A. and A. Mufti. Canadian Society for Civil Engineering, Montreal, pp.64-97.

Li, V.C., Mishra, D.K., Naaman, A.E., Wight, J.K., LaFave, J.M., Wu, Hwai-Chung. \& Inada, Y. 1994. On the shear behavior of engineered cementitious composites. Advanced Cement Based Materials. 1: 142-149.

Li, V.C., Wu, H.C., Maalej, M. \& Mishra, D.K. 1996. Tensile behaviour of cement-based composites with random discontinuous steel fiber. Journal of the American Ceramic Society 79: 74-78.

Meng, D., Huang, T., Zhang, Y.X. \& Lee, C.K. 2017. Mechanical behaviour of a polyvinyl alcohol fiber reinforced engineered cementitious composite (PVA-ECC) using local ingredients. Construction and Building Materials 141: 259-270.

Meng, W. \& Khayat, K.H. 2018. Effect of hybrid fibers on fresh properties, mechanical properties, and autogenous shrinkage of cost-effective UHPC. J. Mater. Civ. Eng. 30: 04018030.

Pakravan, H.R., Jamshidi, M. \& Latifi, M. 2016. Study on fiber hybridization effect of engineered cementitious composite with low and high-modulus polymeric fibers. Construction and building materials 112: 739-746.

Pan, X., Shi, C., Jia, L., Zhang, J. \& Wu, L. 2016. Effect of Inorganic Surface Treatment on Air Permeability of Cement-Based Materials. Journal of materials in civil engg. 28: 1-8.

Pan, Z., Wu, C., Liu, J., Wang, W. \& Liu, J. 2015. Study on mechanical properties of cost-effective polyvinyl alcohol engineered cementitious composites (PVA-ECC). Construction and Building Materials 78: 397-404. 
Ranade, R. \& Li, V.C. 2014. Influence of micro-cracking on the composite resistivity of engineered cementitious composite. Cement and Concrete Research 58: 1-12.

Rathod, J.D. \& Patodi, S.C. 2010. Interface tailoring of polyester-type fiber in engineered cementitious composite matrix against pullout. ACI Materials Journal 107: 114-122.

Redon, C., Li, V.C., Wu, C., Ogawa, A., Hoshiro, H. \& Saito, T. 2001. Measuring and modifying interface properties of PVA fibers in ECC matrix. J. Mater. Civ. Eng. 13: 399-406.

Ronaldo, A.M.J. \& Lima M.G. 2016. Electrical resistivity of unsaturated concrete using different types of cement. Construction and building materials 107: 11-16.

Sahmaran, M. \& Li, V.C. 2008. Durability of mechanically loaded engineered cementitious composites under highly alkaline environments. Cement and Concrete Composite 30: 72-81.

Sahmaran, M. \& Li, V.C. 2009. Durability properties of micro-cracked ECC containing high volumes fly ash. Cement and Concrete Research 39: 1033-1043.

Said, S.H. \& Li, V.C. 2015. Flexural behavior of engineered cementitious composite (ECC) slabs with polyvinyl alcohol fibers. Construction and building Materials 75: 176-188.

Sakulich, A.R. \& Li, V.C. 2011. Nanoscale characterization of engineered cementitious composite (ECC). Cement and Concrete Research 41: 169-175.

Shao, Y. \& Shah, S.P. 1997. Mechanical properties of PVA fiber reinforced cement composites fabricated by extrusion processing. ACI Mater. J. 94: 555-564.

Siddique, R., Kapoor, K., Kadri, E.H. \& Bennacer, R. 2012. Effect of polyester fibres on the compressive strength and abrasion resistance of HVFA concrete. Construction and Building Materials 29: 270-278.

Singh, M., Saini, B. \& Chalak, H.D. 2019 ${ }^{a}$. Performance and composition analysis of engineered cementitious composite (ECC) - A review. Journal of Building Engineering 26: 100851. https://doi.org/10.1016/j.jobe.2019.100851.

Singh, M., Saini, B. \& Chalak, H.D. 2019 . Properties of Engineered Cementitious Composites: A Review. Proceedings of the 1st International Conference on Sustainable Waste Management through Design , pp. 473483. https://link.springer.com/chapter/10.1007/978-3-030-02707-0_54

Soe, K.T., Zhang, Y.X. \& Zhang, L.C. 2013 ${ }^{\text {a }}$. Material properties of a new hybrid fibre-reinforced engineered cementitious composite. Construction and Building Materials 43: 399-407.

Soe, K.T., Zhang, Y.X. \& Zhang, L.C. 2013 $^{\mathrm{b}}$. Impact resistance of hybrid-fiber engineered cementitious composite. Composite Structures 104: 320-330.

Suryanto, B., Takaoka, H., McCater, W.J., Saraireh, D. \& Taha H. 2018. Impedance measurements on an engineered cementitious composite: A critical evaluation of testing protocols. Measurement 129: 445-456.

Tsung, C.H., Kien, N.V., Yu, M.S., Yuan, R.C. \& Pei, J.C. 2017. Effects of coarse aggregates on the electrical resistivity of Portland cement concrete. Construction and Building Materials 133: 397-408.

U.S Patent (No. 4063887), 1977. Method for improving the water absorption of polyester fibers.

Zhigang, Z., shunzhi, Q., Hui \& M. 2014. Investigating mechanical properties and self-healing behavior of micro cracked ECC with different volume of fly ash. Construction and Building Materials 52: 17-23. 